\title{
Place and provision: Mapping mental health advocacy services in London
}

\author{
Ronan Foley $^{\mathrm{a}, *}$, Hazel Platzer ${ }^{\mathrm{b}}$ \\ ${ }^{a}$ Department of Geography/National Institute of Regional \& Spatial Analysis (NIRSA), NUI Maynooth, Maynooth, Co. Kildare, Ireland \\ ${ }^{\mathrm{b}}$ Health and Social Policy Research Centre, University of Brighton, Falmer, Brighton, UK
}

Available online 30 October 2006

\begin{abstract}
The National Health Service (NHS) Executive for London carried out an investigation in 2002 as part of their wider mental health strategy to establish whether existing mental health advocacy provision in the city was meeting need. The project took a two-part approach, with an emphasis on, (a) mapping the provision of advocacy services and, (b) cartographic mapping of service location and catchments. Data were collected through a detailed questionnaire with service providers in collaboration with the Greater London Mental Health Advocacy Network (GLMHAN) and additional health and government sources. The service mapping identified some key statistics on funding, caseloads and models of service provision with an additional emphasis on coverage, capacity, and funding stability. The questionnaire was augmented by interviews and focus groups with commissioners, service providers and service users and identified differing perspectives and problems, which informed the different perspectives of each of these groups. The cartographic mapping exercise demonstrated a spatially - even provision of mental health advocacy services across the city with each borough being served by at least one local service as well as by London wide specialist schemes. However, at local level, no one borough had the full range of specialist provision to match local demographic need. Ultimately the research assisted the Advisory Group in providing commissioning agencies with clear information on the current status of city-wide mental health advocacy services, and on gaps in existing advocacy provision alongside previously unconsidered geographical and service dimensions of that provision.
\end{abstract}

(C) 2006 Elsevier Ltd. All rights reserved.

Keywords: Advocacy; Mental health; Service mapping; Needs assessment; GIS; UK; GLMHAN

\section{Introduction, aims and objectives}

The National Health Service (NHS) Executive London Regional Office established the Advocacy Advisory Group in October 2000 with the aim of integrating advocacy within the scope and remit of

\footnotetext{
*Corresponding author. Tel.: + 35317086024 ; fax: +35317083573 .

E-mail addresses: ronan.foley@nuim.ie (R. Foley), h.platzer@bton.ac.uk (H. Platzer).
}

the London Mental Health Strategy for Action (NHS Executive and Social Services Inspectorate, 2001). As a part of this wider strategic process, a research project was commissioned to look at mapping Mental Health Advocacy Services in London (Platzer \& Foley, 2004). This paper surveyed the state of mental health advocacy service provision in London in 2002 and used 'mapping' in two of its different meanings, cartographic and service-specific. This reflected the different thrusts of the paper in wishing to look at where services were 
located geographically and also to identify what specific services existed, how they functioned and who they served. The 'place' of advocacy services was explored in relation both to their spatial location and their position within wider issues of need, access and health inequalities.

Advocacy can be generally understood as any action to assure the best possible services for or intervention in the service system on behalf of an individual or group. Specifically, advocacy is the activity of an individual to pursue and act in the interests of another where the latter defines his or her own interests and through the process of advocacy gains a certain degree of power to pursue them (NHS Executive and Social Services Inspectorate, 2001). There are a variety of models of advocacy provision ranging from individual and group advocacy to non-instructed advocacy (Foulks, 2000; Morselli \& Elgie, 2000; Scottish Human Services Trust, 2002). By mapping existing services within the Greater London area, the extent to which different and dominant models of advocacy were used across the city would be clarified, as well as the extent to where different models of advocacy were available to meet potential need.

With the initial aim of the project being to look at mapping mental health advocacy services, there were a number of objectives implicit in this process. One objective was to map the geographical location of services in relation to expressed and potential need for those services. This approach was intended to enable spatial identification of service provision matched against potential need, identify areas that were well served but also to identify gaps and areas that were under-served. From a service perspective, a second objective was to look at the capacity, stability and funding of advocacy services within London with a particular brief to identify gaps in service provision against existing models of advocacy use. A final objective was to look at specific models of advocacy provision by type, resourcing and client group. This latter approach included additional qualitative information gleaned directly from advocacy users, providers and commissioners.

\section{Literature review}

As the study combined background information on Mental Health Services with specific aspects of advocacy and linked these together with spatial elements of health care planning, this necessitated a broad approach to the literature. The literature on advocacy, Mental Health Service planning and wider health geographies are treated here in turn and represent an original combination of contextual elements.

\subsection{Advocacy provision and mental health}

Existing models of advocacy provision were reviewed for the purposes of identifying how inequalities and vulnerabilities with regard to mental health mapped onto the provision of advocacy. Key initial questions included: who provided advocacy, what kinds of issues were taken forward and in which settings was it provided? Advocacy is traditionally provided in the settings where it is most needed. In the case of mental health, this is often within the acute and secondary settings of specialist hospitals or prisons but is also found (though perhaps to a lesser extent) in community settings. There is also a distinction between models of advocacy (self, individual, peer, group and citizen, issue-based and instructed) and within these broad models, specific types of advocacy (financial, legal, non-instructed) (Atkinson, 1999).

Advocacy schemes need to be available to a wide variety of users including those from minority groups. Availability of advocates from black and minority ethnic groups can help to increase access for black and minority ethnic users (Atkinson, 1999; Henderson \& Pochin, 2001). Similarly, advocacy services are more accessible to lesbians and gay men if a lesbian or gay advocate is available (Platzer, 2000). Many health advocacy schemes working with minority groups have argued that it is necessary to provide a holistic service which includes advice and advocacy about housing and welfare benefits and support as well as issue-based health or mental health advocacy (Baker et al., 1997; Grimshaw, 1996; Oliver \& Warwick, 2004) This did not fit well though with the current dominant model of specialist mental health advocacy, which tended towards issue-based advocacy, focused on a shortterm intervention around a specific aspect of a mental illness.

The question of what advocacy was provided was considered in relation to need, setting and the role of advocacy and was affected by the complexity of advocacy need. Issues-based advocacy worked well up to a point in acute hospital environments but we had to question if it was as effective in community settings. We also asked to what extent the issues- 
based approach could challenge the culture of an organisation. Recent government, and other, reports have revealed the gross neglect of acute psychiatric in-patient services and ensuing poor standards of care (Department of Health, 1998; The Sainsbury Centre for Mental Health, 1998). In the light of these reports it clearly made sense to target mental health advocacy resources to acute admission settings in hospitals. However, there were several reasons for considering the impact of focusing solely on these areas. The first of these was that discharged patients may have been languishing in the community unable to get treatment reviewed or may have been under threat of readmission if they did not comply with treatment. The second reason was in relation to prevention; much of the disproportionate sectioning, compulsory treatment and misdiagnosis of black people has been put down to poor access to primary care (Bhui, 1997; Rai-Atkins, 2002; Smaje, 1995; Silvera \& Kapasi, 2000). This situation might be alleviated by improvement in primary care so providing mental health advocacy in such settings could be the key to such improvements (Wilson \& Francis, 1997). Given the damaging effect of compulsory detention more mental health advocacy in community settings could only be a good thing in this respect (Barnes, Davis, \& Tew, 2000). Furthermore, early access to therapeutic care could be more easily advocated for if advocacy schemes were located in places where people first tried to access care; for instance some groups of people, such as refugees and asylum seekers, initially tried to access care through emergency and accident departments (Silvera \& Kapasi, 2000). The third reason for considering extending mental health advocacy services into the community was because this may have been the most effective way of increasing user involvement and challenging policies which determined the culture within psychiatric services (Gell, 1990; Munn, 2001; Rogers \& Pilgrim, 1996).

\subsection{Mental health care planning}

The relationship between mental health needs and social exclusion was evident and not all service users had access to mental health advocacy (Dunn, 1999; NHS Executive, 2001). We looked at this in more detail by focusing on the demography of mental health in London. There were a number of methods to estimate mental health and by extension, advocacy demographics. The existing literature identified a number of key groups who displayed relatively high susceptibility to mental health problems (Johnson et al., 1998; Thornicroft, 1991). Mapping where these groups were located enabled the planning process for different sections of Mental Health Service delivery, forecasting and demand.

Groups who displayed high levels of mental health problems in London included minority ethnic groups, especially African-Caribbeans, as well as refugees and asylum seekers, the homeless, the 16-44 year old age group, people living alone, prison populations and those affected by unemployment, poverty and deprivation (Chahal, 1999; Glover, Leese \& McCrone, 1999; Johnson \& Taylor, 2001; Johnson et al., 1998; The Health of Londoners Project, 1998). The vulnerability factors predisposing people to mental health problems included social and geographical isolation, stigma, gender, poverty and ability to communicate (Scottish Executive, 2001). So in addition to the groups already identified as being likely to have particular mental health and advocacy needs, we added other dispersed or excluded groups such as lesbians and gay men, travellers, carers, people with hearing impairments and the homeless (Carers Advisory Group, 2001; London Research Centre, 1999; Matz, Hill, \& Heath, 2001; SIGN, 1998).

The existing literature also provided some valuable pointers in estimating need. Without going into extensive detail, some key proportions were collected in previous studies (Harrison, Barrow, \& Creed, 1995; Harvey, 1996; Meltzer et al., 1995). Estimates for London showed an estimated prevalence rate for psychosis of $0.4 \%$, while this can reach $2 \%$ in some inner-city areas. An estimate for Kensington, Chelsea and Westminster gave a figure of $0.72 \%$ (Gath \& Higginson, 1995). The rates here were higher for minority ethnic populations, especially of African-Caribbean heritage (Curtis \& Lawson, 2000; Davies, Thornicroft, Leese, Higgingbotham, \& Phelan, 1996; Travers \& Minors, 1995). Amongst the homeless, around $30-50 \%$ were estimated as having psychotic mental illness (Scott, 1993). Other high rates (40-50\%) were recorded for prison populations (Johnson \& Taylor, 2001). It was very difficult to match hospital-based admission data with estimates of need in the general population based around the above rates of incidence. One example where a broad match was probable was the relatively high age/sex standardised admission ratios (SAR's) for psychiatric diagnosis in inner city districts. For this latter group, the highest 
average numbers were in central districts such as Newham, Haringey and Hackney.

The literature was also reviewed to consider issues related to funding of mental health advocacy services. There was a relationship between prevailing models of mental health advocacy and funding arrangements. This relationship made it difficult to provide advocacy services for groups of people whose needs did not map neatly onto these prevailing models making it difficult to fill the gaps in services. Increasingly funding bodies preferred definitions and models of advocacy where there were clear and measurable outcomes. Such approaches worked best with issues-based advocacy, which was also known as technical or case-work advocacy and tended to be instructed by the client. As government policy, in the current reform of the Mental Health Act (1983), moved towards the right to specialist mental health advocacy for patients subject to compulsory powers, this position was likely to become more entrenched (Barnes, 2001). This was particularly worrying when we considered that many non-sectioned patients were subject to coercion and the threat of detention but they may not have been prioritised to receive mental health advocacy if legislation developed in the way anticipated (Rose, 2001). Within the advocacy movement there was a call to question the extent to which an instructed model of advocacy could always be empowering and may have lead to schemes failing to advocate on complex issues (GLMHAN, 2001). Experience had shown that uptake of advocacy improved when a variety of approaches were used; for example, uptake of a legal advocacy service increased after the establishment of a patient council support group (Robson, 1987).

It was well known that small voluntary sector mental health advocacy schemes spent a disproportionate amount of their time trying to secure their short-term future. This made it difficult to develop the infrastructure needed to support the scheme and made it especially difficult for groups trying to provide schemes for minorities (Curran \& Grimshaw, 2000; Scottish Executive, 2001; Silvera \& Kapasi, 2000). It even lead ironically, to the voluntary sector competing with users for funding (Brandon \& Simpson, 2001). This situation had to be understood within the dominant culture of "best value" in which competitive tendering had become a norm (Henderson \& Pochin, 2001). What was perhaps most worrying about the current climate for funding, was the way it could determine the kind of advocacy provided.

\subsection{Health geographies}

The location of Mental Health Advocacy services was a second key element for consideration. Service location was often a key factor in effective delivery and a consideration of where services were, what type of service they delivered and the amount of advocacy support provided were all important in a broader mapping setting (Joseph \& Phillips, 1984; Phillips, Kinman, Schnitzer, Lindbloom, \& Ewigman, 2000). In this way geographical as well as service gaps were identified. When mapped against expressed or potential need at broad spatial levels, this process identified those parts of London where there were potential inequalities and gaps.

With the advent of ICT-based approaches like geographic information system (GIS), the use of cartographic approaches to health care planning have become much more common, with particular interests in catchments, location-allocation, equality of provision and spatial modelling of health inequalities (Gatrell \& Senior, 1999; Lewis, 2001; Pyke, Morris, Rabin, \& Sabriye, 2001; Richards, Croner, Rushton, Brown, \& Fowler, 1999; Stevenson, 2001). There is also a developing GIS-based geography of Mental Health Service mapping within the UK (Bhana \& Pillay, 1998; Dembling, Li, Chang, Mackey, \& Merwin, 2001; Department of Health, 1998; Milligan, 2000). More traditional quantitative methods and spatial approaches were used however, to estimate Mental Health and, by extension, advocacy demographics. These approaches were used in several surveys and are described much more comprehensively in a set of related reports partly commissioned by the NHS Executive (Fitzpatrick \& Jacobson, 2001; Johnson et al., 1998; The Health of Londoners Project, 1998). Mapping information on mental health through a GIS provided an additional and flexible tool to aid planning for different aspects of Mental Health Service delivery, forecasting and demand, and also tried to incorporate a more 'peoplecentred, approach (Gatrell \& Senior, 1999; McLafferty 2003; O'Dwyer \& Burton, 1998). The value of a GIS approach in a functional setting, however, was that these varied additional geographies of mental health were easy to reproduce for visualisation and planning purposes (Bullen, Moon, \& Jones, 1996; Hirshorn \& Stewart, 2001; Rushton, 1998). Some 
care should additionally be exercised in using these data as they represented different measures of mental health in different ways and for different areal units. Additional acknowledged problems, related to the modifiable areal unit and associated ecological fallacy. The level and scale of aggregation may have hidden more localised clusters and additionally the choice of areal unit affected they way the data appeared and again modified genuine clusters within the data (Joseph \& Phillips, 1984; Jones \& Moon, 1987; Jones \& Moon, 1987; Openshaw, 1984).

While quite disparate in their subject matter and contexts, there has also been a substantial literature on geographies of mental health, which focused on a number of key associations between health and place (Curtis \& Taket, 1996; Gatrell, 2002; Kearns \& Gesler, 1996). This has been primarily characterised by linking interests in place (geography and setting) and relating this to spatial health service issues of need, access and provision. The work of Giggs and Cooper (1987) focused on the relationship between the clustering of mental ill-health in city centre areas and how this might have an explanation associated with proximity to services, while issues of mobility also arose in the work of Lamont, Ukoumunne, Tyrer, Thornicroft and Slaughter (2000). Dear and Wolch (1997) focused on the impacts of de-institutionalisation of mental health provision on local geographies of mental health in cities, a pattern common to many western societies. Discussions around their notion of a 'service dependent ghetto', as well as other factors, which helped identify landscapes of power in relation to mental health in cities, are succinctly summarised in Curtis (2004). Recent concerns with such landscapes in a 'post-asylum' geographical setting were also outlined in a special issue of Health \& Place from 2000, specifically in a paper by Wolch and Philo (2000). They identified a number of key directions for geographers working in mental health, in particular concerns with '(dis)place ment models' of service delivery and pointed in particular to the work of Hester Parr (1997, 1999). Parr's work formed a key background to studying advocacy through explorations of geographies of resistance and their relationships with strategic coalitions and it was a useful theoretical area into which to place the work of the Greater London Mental Health Advocacy Network (GLMHAN) as part of what Parr refers to as 'a collective identity, formed through sociospatial association'
(Parr, 1997, p. 438). This research sought to explore some of these issues in a service delivery setting with a specific emphasis on the role of advocacy.

\section{Methodology}

Quantitative and qualitative information was gathered in a number of forms. The quantitative data aspects of the study pulled together topographic, demographic and service location data that in turn were fed into a GIS (ArcView 3.3) for cartographic and statistical analysis. Qualitative data was gathered through a service mapping survey and additionally, through a series of interviews and focus group meetings with service providers, commissioners and users.

The methodology for the project was structured to incorporate several broad data collection and analysis approaches. These included information gathered on the location of services alongside specific service provision and utilisation data and provider/user perspectives based on information gathered through interviews and focus-groups. The key data source was the collection of detailed information on existing advocacy provision, based on updating a 1998 database of agencies providing mental health advocacy collated by the GLMHAN. Additional sources of service information in 2002 were collected via databases held by the Advocacy Across London (AAL) and Citizen Advocacy Information and Training (CAIT) organisations and the National Association for Mental Health (MIND). Further information for cross-matching was gathered from organisations including the National Schizophrenia Fellowship (NSF), Carers UK, National Association of Citizens Advice Bureaux (NACAB), National Association of Voluntary Organisations (NCVO), the National Youth Advocacy Service and the NHSE Mental Health in London Strategy for Action. Additional spatial data was collected from the NHS, National Statistics and the London Public Health Observatory.

The agencies providing advocacy in 1998 were contacted through direct phone calls to check their current status. They were also cross-checked in consultation with the centralised agencies listed above. A final list of 57 organisations was identified which were funded to provide mental health advocacy in London. A revised and augmented survey was piloted on seven organisations including all those based within one individual borough and others that provided a London wide service. 
Questions were designed to enable appropriate spatial analysis as well as elucidate more specifically qualitative aspects of service provision. The questions focused on the following issues:

- location of service and service catchments;

- opening hours;

- caseload;

- age, ethnicity and status under the Mental Health Act (1983) of clients;

- proportion of cases in hospital and the community;

- staffing levels;

- user involvement;

- models of advocacy used and types of advocacy provided;

- specialist services and interpreting services;

- perceptions of local need;

- self-assessed gaps in provision; and

- sources, levels and stability of funding.

Twenty nine agencies (51\%) responded directly, which was about average for similar postal or electronically delivered surveys (Silvera \& Kapasi, 2000). It was also noted that over half of the nonrespondents were non-contactable due to the closure or amalgamation of the service since 1998, a telling comment in itself on the stability and longevity of advocacy provision. Other potential explanations of non-response related to the potential for the advocacy service to be hidden within bigger organisation. Postcodes for each organisation's location were obtained, enabling all services to be geographically mapped and linked to their questionnaire responses for analysis within the system.

From the point of view of assessing, mapping and modelling need, spatially-based data were collected at ward, district and health authority level. These included data derived from the census and local surveys on specific mental health acute admission rates as well as a wider set of data variables that related to 'at-risk' populations (Johnson \& Taylor, 2001; Johnson et al., 1998). These ranged from measures of deprivation to levels of homelessness, ethnicity, levels of alcohol consumption as well as key demographic data on age and gender. Data were collated at aggregated levels (to avoid smallnumber problems) for key groups including the elderly, the young, black and minority ethnic groups, refugees and asylum seekers, lesbians and gay men, the homeless, carers and offenders. These groups were chosen as appropriate based on the responses of service-users, service providers and commissioners as well as from those groups identified in the literature.

A final source of qualitative data was via a set of interviews and focus groups. Focus groups were used as an appropriate method to gather multiple views and was deemed particularly appropriate in a mental health advocacy setting where issues of power and ownership were acute (Morgan and Kreuger, 1993). The original brief from the advisory group asked for six focus groups to be conducted of which four would be with advocacy providers, one with Mental Health Service commissioners, and one with users of advocacy services. However, the uptake of invitations to focus groups was less than expected amongst advocacy providers and greater than expected amongst user groups. Given this response and the findings from the literature, the balance shifted to more consultation with users and support groups and less consultation with advocacy providers. Additional focus groups with 10 "forensic patients" and with 20 Mental Health Service users in the community were conducted as part of another project but helped inform the findings (Platzer, 2002). Due to practical organisational issues, a short postal questionnaire was devised and sent to 19 PCT Chief executives for the attention of their Mental Health commissioners. The survey was returned by 12 commissioners, which was a response rate of $63 \%$.

All of the organisations participating in the survey were invited to attend the focus group for advocacy providers. In addition representatives were sought from schemes, which had evolved from the work of the London Mental Health Strategy and other advocacy groups whose work might overlap where clients had dual needs. These invitations went then to groups working with black and ethnic minorities, carers and people with learning disabilities. Four people attended the focus groups for advocacy providers and they represented borough wide mental health advocacy schemes. Additionally, one worker from a refugee support service and three workers from a support service for Black African-Caribbean people attended the user groups.

\section{Analysis and results}

\section{Geographical mapping}

The GIS was populated initially with a wide variety of data variables relevant to the mapping of 
Mental Health needs assessment. This made it relatively easy to identify spatial concentrations of different risk groups at different scales across the city as a whole. The principal geographies used were wards; local authority districts/boroughs, health authorities (pre-2001) and Mental Health Trust areas. Due to the volume of data variables available, it is sensible to reproduce only one or two exemplars within this paper.

The summary data in Fig. 1 focused more specifically on acute and outpatients data as direct measures of Mental Health need and utilisation. Information on the areas that had the highest standardised admission rates were mapped and identified a geography of expressed need. These included several districts in the north, east and central parts of the city, such as Camden, Ealing, Hammersmith and Hounslow as well as east London and Lambeth. The lowest rates and figures were generally recorded in suburban areas such as Barnet, Bromley and Croydon (Johnson et al., 1998; Morgan, Bardsley, \& Dawson, 2000). These patterns were confirmed when the data was visualised at ward level from within the GIS and showed that the greatest concentrations were again in the north central part of the city. This simultaneously showed the value of being able to represent such a mass of data in a comprehensible and immediate form. Indeed, though not shown here, the data at ward level brought out further pockets of need in areas, such as Redbridge and Lambeth, which were perhaps 'hidden' when mapped at a broader spatial scale, a problem alluded to previously (Gatrell, 2002).

Having identified some initial data on spatial patterns of need and utilisation, the next stage was to overlay the relevant spatial information from the Mental Health advocacy services as collected via the questionnaire. Because of the response rate to the questionnaire $(51 \%)$ it was difficult to fully summarise the precise status of services but it did however, provide valuable information on the current location, by postcode of service headquarters and catchments in London in 2002. The information summarised below will initially concentrate on key spatial aspects of those service responses while service specific issued will be more fully explored in the subsequent section.

Fig. 2 shows the distribution of Mental Health Advocacy Services in 2002. These differed somewhat from the services available in 1998. The data updating process identified that around a quarter of groups providing advocacy four years previously were either no longer functioning or were operating in a different way. This highlighted the fact that one of the key factors in the original aim, the identification of the stability and capacity of service provision, remained a problem due to on-going difficulties with short-term funding and fluidity in service provision. There was a general spread across the capital though there is a greater density, as

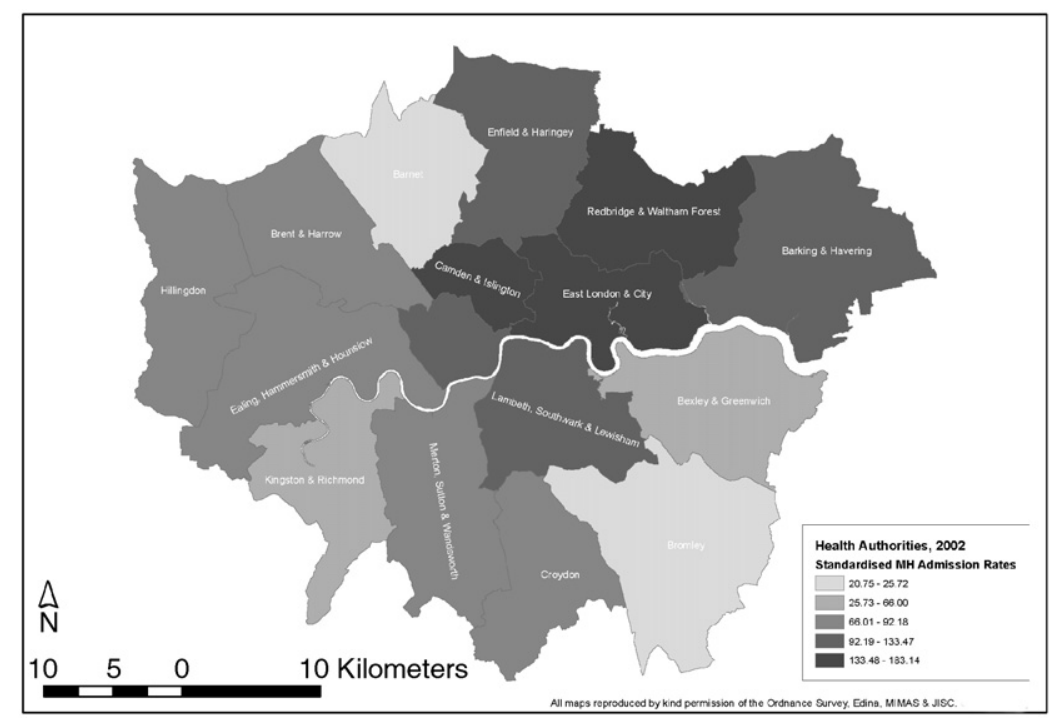

Fig. 1. Mental Health standardised admissions rates by Health Authority Area, London 1998. 


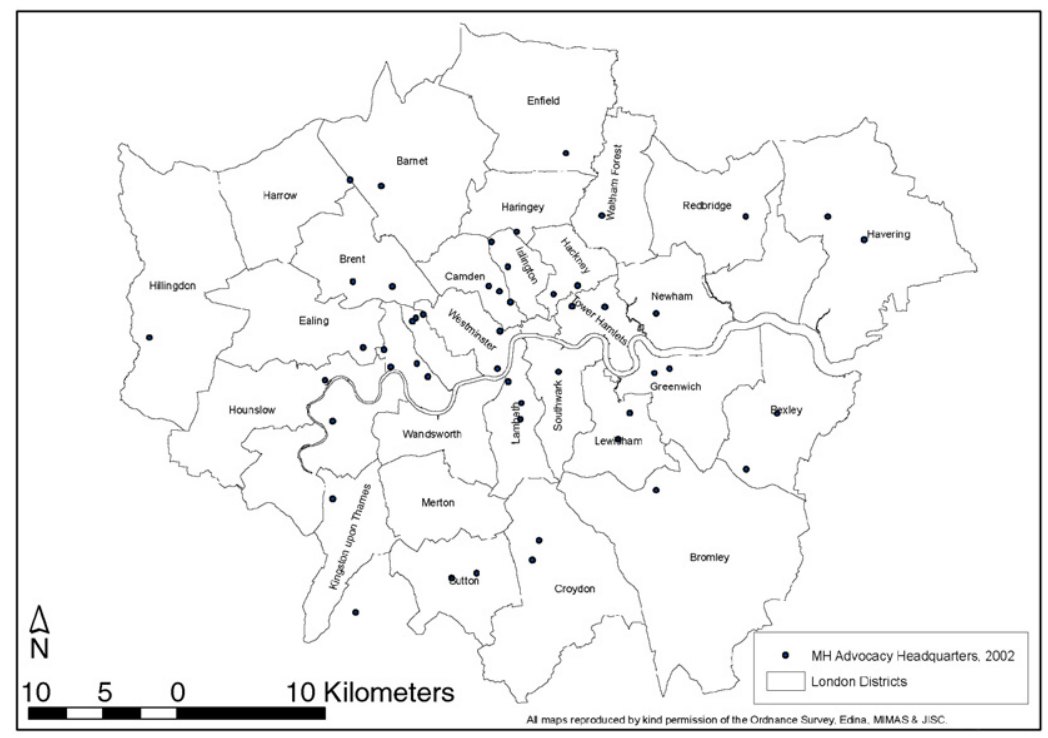

Fig. 2. Location of Mental Health Advocacy Services in London 2002.

would be expected, in the city centre north, to coincide with the greatest concentrations of need as measured by admission rates. There was also a noticeable lack of provision in East London, another area identified with high SARs. The location of advocacy services were also summarised in terms of the size, extent and specialism of the services provided. A relatively large number of the services (18 or 62\%) listed advocacy as their primary activity.

This aspect of service mapping was one of the questions within the survey. The results suggested that for those services that provided information, they were devoting an average of $54 \%$ of the service to Mental Health Advocacy. Quite a number of these were providing a $100 \%$ service whereas for other services it was a much smaller proportion. To get a better sense of this spread, a rough coding of these proportions was mapped in Fig. 3. This showed that around half of the services provided $100 \%$ advocacy and were split $2 / 1$ in terms of the River Thames, with 10 to the north and 5 to the south. It should be reiterated that the questionnaire response meant that although a number of other $100 \%$ advocacy services clearly existed, they had not returned information. In particular this related to a cluster of services in Kensington \& Chelsea and Hammersmith \& Fulham as well as some of the city centre districts. These were all areas that were known to have a considerable need based on both service use and risk factors.
Each service had a different catchment, as defined by the organisation itself. A number of the services such as PACE, NSF, POPAN and others (seven in total) provided a service which covered the whole of the Greater London area, but the majority of the services were tied in to District or Health Authority boundaries. These would be confusing to map due to the number of overlapping boundaries, so it was more useful to aggregate the number of services serving each district and health authority to get a better sense of the volume of service provision across the city. These data are summarised in Table 1. In general, there was quite an even spread with a range of $8-10$ services available at District level and a range from 8 to 12 at the larger Health Authority level. The districts which appeared to be best served included Brent, Camden, Croydon, Hammersmith \& Fulham, Islington and Richmond while those least served included, Wandsworth, Merton, Kingston, Hillingdon, Harrow, Haringey, City and Barking. This again seemed to indicate that the Inner-Outer London split broadly applied to advocacy service provision as well. Some of these outer districts in the north-east (Waltham Forest and parts of Redbridge) and west (Hillingdon) seemed to be least well served even though they had high admission rates (Fig. 1). There was a suggestion here that due to the spatial concentration of acute settings in city centre areas, provision may not have kept pace with human mobility factors (Curtis, 2004). 


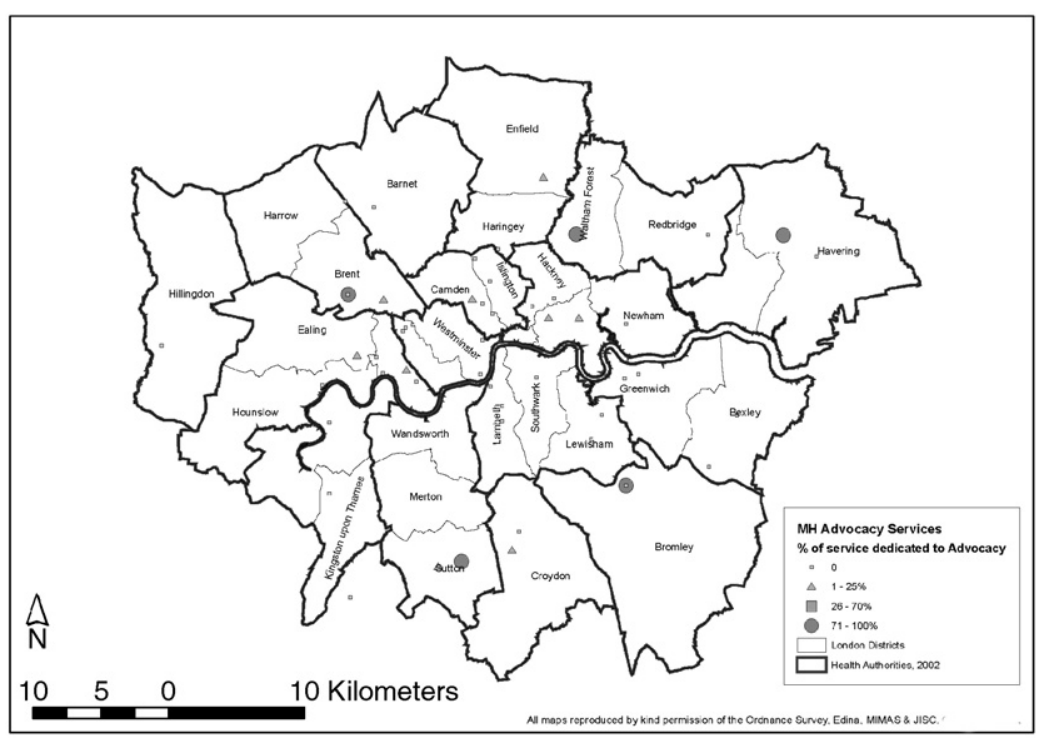

Fig. 3. Proportion of individual services dedicated to advocacy in London, 2002.

Table 1

Mental Health Advocacy Service Provision by Health Authority, 2002

\begin{tabular}{lll}
\hline London Health Authority & $\begin{array}{l}\text { No. of MHA } \\
\text { service HQ's in } \\
\text { HA }\end{array}$ & $\begin{array}{l}\text { Number of } \\
\text { MHA agencies } \\
\text { serving HA }\end{array}$ \\
\hline $\begin{array}{ll}\text { Barking \& Havering } \\
\text { Barnet }\end{array}$ & 2 & 9 \\
Bexley \& Greenwich & 2 & 9 \\
Brent \& Harrow & 2 & 11 \\
Bromley & 1 & 10 \\
Camden \& Islington & 5 & 9 \\
Croydon & 2 & 12 \\
Ealing, Hammersmith \& & 5 & 10 \\
Hounslow & & 12 \\
East London \& City & 5 & 12 \\
$\begin{array}{l}\text { Enfield \& Haringey } \\
\text { Hillingdon }\end{array}$ & 2 & 10 \\
Kensington, Chelsea \& & 1 & 8 \\
Westminster & 5 & 11 \\
Kingston \& Richmond & 2 & 10 \\
Lambeth, Southwark \& & 6 & 12 \\
Lewisham & & \\
Merton, Sutton \& & 2 & 9 \\
Wandsworth & & \\
Redbridge \& Waltham & 2 & \\
Forest & & \\
\hline
\end{tabular}

\section{Service mapping and advocacy service statistics}

Some of the cartographic summaries listed above were by definition simplistic and hid a number of important variations in actual service provision. As well as mapping the location of services and identifying gaps visually, a second aim of the study was to look more closely at quantitative data on relative service size, staffing and funding as well as specialist provision and models/types of advocacy encountered. Some core data are summarised in Table 2.

Funding varied across the services and ranged from $£ 19,812$ /annum to $£ 450,998$ with an average of $£ 143,258$ for those services $(n=26)$ who provided information on funding. There were some caveats concerning these figures, specifically relating to the amount devoted to advocacy, which will be further discussed below. This still indicated a considerable range in amounts of funding for services and this was emphasised further by the data on staffing. The staffing of full-time equivalent staff (ftes) ranged from 0.6 to $17 \mathrm{ftes}$ with an average of 4.8 . The number of clients, as expressed by estimates of the number of new cases a year, averaged 206/service and also gave an estimated total user figure of 5976 based on those organisations who had provided this data $(n=29)$. This also suggested that individual staff case loads for new cases averaged out at around 43, which with repeat visits and existing case loads suggest that advocacy service staff were fully occupied under the then current conditions (Johnson et al., 1998; Stevenson, 2001).

Other findings from the survey identified that the bulk of the funding for the advocacy organisations, 
Table 2

Summary Service Provision Data for Mental Health Advocacy Agencies, London 2002

\begin{tabular}{|c|c|c|c|}
\hline Variable & Mean & Minimum & Maximum \\
\hline Funding $(n=26)$ & $£ 143,258$ & $£ 19,812$ & $£ 450,998$ \\
\hline $\begin{array}{l}\text { Statutory funding } \\
(n=25)\end{array}$ & $76 \%$ & $0 \%$ & $100 \%$ \\
\hline $\begin{array}{l}\text { Voluntary (charity) } \\
\text { funding }(n=26)\end{array}$ & $21 \%$ & $0 \%$ & $100 \%$ \\
\hline $\begin{array}{l}\text { Central Govt. } \\
\text { funding }(n=26)\end{array}$ & $3 \%$ & $0 \%$ & $47 \%$ \\
\hline $\begin{array}{l}\% \text { of service proving } \\
\text { advocacy }(n=29)\end{array}$ & $54 \%$ & $0 \%$ & $100 \%$ \\
\hline $\begin{array}{l}\text { New cases per annum } \\
(n=29)\end{array}$ & 206 & 0 & 760 \\
\hline $\begin{array}{l}\% \text { sectioned under } \\
\text { MHA }(n=29)\end{array}$ & $44 \%$ & $0 \%$ & $95 \%$ \\
\hline $\begin{array}{l}\% \text { under home office/ } \\
\text { court order }(n=29)\end{array}$ & $4 \%$ & $0 \%$ & $60 \%$ \\
\hline $\begin{array}{l}\% \text { of minority ethnic } \\
\text { group origin }(n=29)\end{array}$ & $35 \%$ & $0 \%$ & $100 \%$ \\
\hline $\begin{array}{l}\% \text { in hospital at first } \\
\text { contact }(n=29)\end{array}$ & $34 \%$ & $0 \%$ & $100 \%$ \\
\hline $\begin{array}{l}\% \text { receiving } \\
\text { community care at } \\
\text { first contact }(n=29)\end{array}$ & $28 \%$ & $0 \%$ & $100 \%$ \\
\hline $\begin{array}{l}\% \text { with no service at } \\
\text { first contact }(n=29)\end{array}$ & $28 \%$ & $0 \%$ & $100 \%$ \\
\hline FTE staffing $(n=29)$ & 4.8 & 0.6 & 17 \\
\hline
\end{tabular}

$76 \%$ on average, still came from statutory sources, mainly health and social services. A further $21 \%$ on average, came from voluntary sources while an average of only $3 \%$ came from government funding. For a large number of organisations $(25 \%$ or $86 \%)$, all of their funding came from the first two sources, while the most that any one organisation got from central government funding was $47 \%$. The security and length of funding was much more of an issue. Of those agencies that provided an answer to the question on the longest period of secured funding, only one answered 4 years with all the rest being 3 years or less with an average of just 2 and a quarter years.

Other results from the questionnaire brought out a picture of the mix of users whom the Advocacy Services were working with. An average of $30 \%$ of clients per service had been hospitalised under various sections of the Mental Health Act (1983) while an average of $4 \%$ of clients per service were under Home Office or Court Order restrictions. The service providers were also asked about client's status at first contact and the results $(n=29)$ of this question also showed a fairly even spread.
The averages for users who were in hospital at the time of first contact was $44 \%$ while the average proportion for those receiving community care at the time of first contact was $28 \%$. An additional $28 \%$ were not receiving any statutory health care at the time of first contact. This gave a relatively even three way split across the board and provided additional information for the estimation of specific Mental Health Advocacy need rates, discussed below.

A final summary statistic was that the average proportion of patients from minority ethnic group backgrounds was $35 \%$, a figure above the total proportion of non-white groups in London as a whole (estimated by National Statistics at $28 \%$ in 2000-2001). This suggested that as for other forms of Mental Health Services, demand for advocacy was also disproportionately high among minority ethnic groups.

Returning to the data on funding and caseloads it was possible to plot an indication of the relative amounts of funding, for those services that provided this information. To be more meaningful the figure for total service funding needed to be weighted by the proportion of the service dedicated to advocacy and new caseloads for that service. This is shown in Fig. 4 and indicated a pattern that was varied across London. Those services with high relative rates of funding for advocacy were quite randomly spread and did not necessarily match the areas of greatest need, especially north of the River Thames. Indeed the highest rate of provision was just under $£ 3500 /$ case, which was still well above the average funding per advocacy case of $£ 453.83$. It was also a relatively high figure as it was based on current caseloads. The funding levels would be even lower if the mapped funding was revised to take account of potential admissions. This was however, difficult to map as it would have been mapping point data on funding against area data for potential demand. Despite the results, it would be difficult however to suggest that there was an 'inverse care law' in action where the funding was inversely related to need (Joseph and Philips, 1984). It seemed more likely that funding and staffing as suggested in the detailed questionnaire responses, was much more closely tied to good infrastructures and successful funding bids rather than a simple need model. Whether this would be an appropriate mechanism to model inequalities in service provision remains to be explored.

Estimates for Mental Health need as measured by in-patient, admissions and outpatient numbers have 


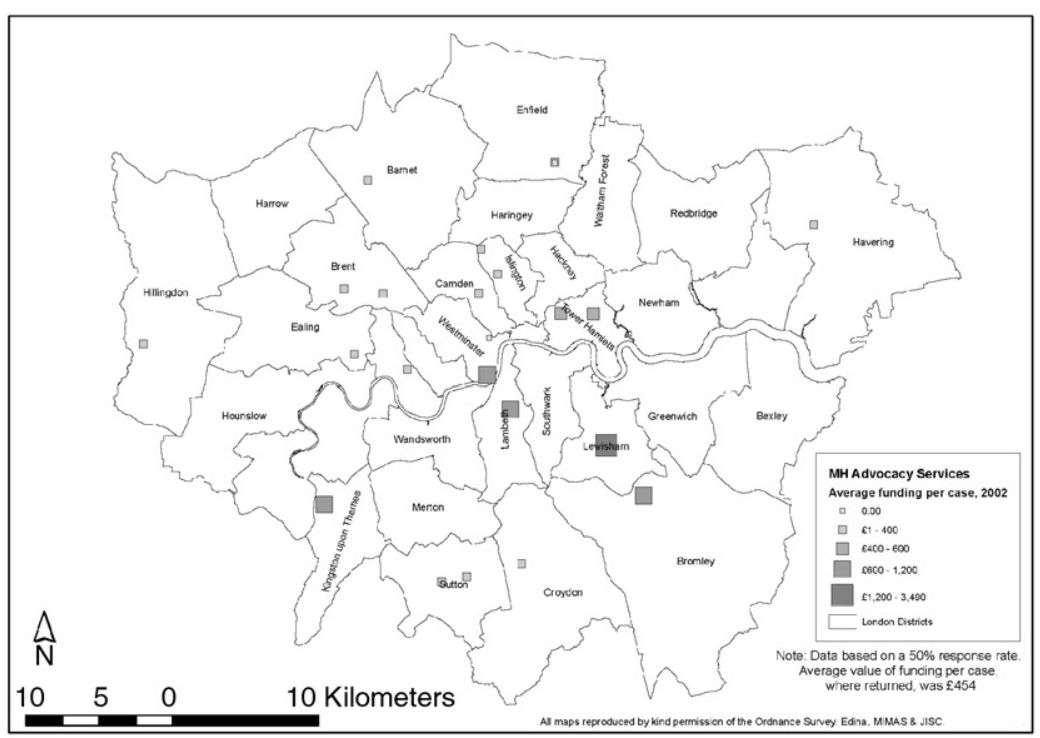

Fig. 4. Average funding per advocacy case, London 2002.

already been mentioned. The numerical client data gathered from the survey of Mental Health Advocacy, while not without its limitations, was helpful, when combined with this other data, in providing some useful starting points for calculating a multiplier for specific advocacy need. Depending on what measures of Mental Health admissions were used this gave an advocacy 'need' measure of anything from $24 \%$ to $39 \%$ of total Mental Health cases, though these were by definition very rough estimates. For example if the figure of 5976 is an estimate for around $54 \%$ of the service providers, then the figure could be extrapolated (allowing for similar average numbers for the remaining missing services) to suggest that there were approximately 9960 current users of Advocacy Services across London. This was, by definition, an under-estimate as virtually all of the services that responded suggested they were at breaking point dealing with the existing and new cases and demand was always greater then provision. Figures for the average length of case were even more problematic and the range ran from an hour to years. It was very difficult to suggest any meaningful length of case from the data provided.

The mapping exercise and consultation showed that there was a reasonably equitable provision of Mental Health Advocacy across the capital with each borough being served by at least one local service as well as by London wide specialist schemes. However, at local level, no borough had the full range of specialist provision, which matched local demography. Furthermore, no one organisation has a full range of specialist provision or delivered their services in a full range of settings based within both acute and community care. Another example of information gathered from the questionnaire, which was also mapped, was the provision of specialist advocacy services for minority ethnic groups. These were relatively limited in both number (10 in total, of which only five were dedicated to specialist groups) and distribution with an unconvincing match between location and demand as measured by high rates of minority ethnic populations. Gaps were also identified in provision for many groups who had other specialist needs (Buston, 2002).

Many of these groups benefited most from a style of advocacy, which incorporated both personal advocacy with support and working with communities (Foulks, 2000; Morselli \& Elgie, 2000). It was also the approach most likely to enable closer working in the community and to increase capacity for user involvement and empowerment. However, the survey also clearly identified the continued dominance of instructed models of advocacy with $100 \%$ of respondents providing individual advocacy and almost $70 \%$ providing self-advocacy. The other most prominent models of advocacy were group $(54 \%)$ and peer (31\%) advocacy. Of the individual types of advocacy the most common were housingrelated $(88 \%)$, advocacy on benefits and finances 
$(69 \%)$ and legal advocacy $(50 \%)$. Less than a quarter $(23 \%)$ were providing advocacy for specialist needs like carers.

\section{Qualitative feedback}

While the results of the survey and mapping exercise identified some key quantitative information on Mental Health Advocacy provision in London, it was also important to feed in a more qualitative perspective to give the survey a more pragmatic and user-based perspective. Interviews with service providers, additional qualitative comments on the questionnaire and the focus groups provided extensive information, which can only be summarised here. The comments did however, provide additional perspectives on service provision linked to location, place and setting.

Although some organisations were funded to provide advocacy in the community many were working at full capacity providing a hospital-based service. Some were not funded to provide advocacy in the community and had serious ethical dilemmas if approached by a service user prior to hospital admission. There was agreement that ideally Mental Health Advocacy should be provided in primary care, community settings, including residential homes, and in emergency and accident departments as well as out of hours. There was only one Mental Health Advocacy Organisation in London, which had a project specifically in primary care. Given the disproportionate number of black Mental Health users, their lack of access to appropriate primary care and high rates of misdiagnosis regarding psychiatric morbidity for black and minority ethnic groups in primary care, it seemed logical to increase capacity for advocacy in primary care settings (Bhui, 1997; Silvera \& Kapasi, 2000; Smaje, 1995). Of those organisations participating in the survey less than a quarter targeted service users in community care settings. There did not appear to be any Mental Health Advocacy Services located in Accident and Emergency departments in London. There was general agreement that out of hours services were needed to allow representation at CPA meetings and MHA assessments.

There was also a perceived need for more legal advocacy to which there were two aspects. The first was the problem of time and resources involved in simply finding a solicitor to act. Even where a solicitor could be found, their style of "best interests" advocacy was often at odds with the referring scheme. The second issue was that advocates themselves needed access to legal advice in order to fulfil their role. This had been available through MIND for a limited time and was an invaluable service but it was no longer available when this study was conducted.

Other gaps related to different age groups. Very few "generic" Mental Health Advocacy Schemes $(17 \%)$ were funded to provide advocacy for people under the age of 18 even though they may have been in-patients in adult acute services. A gap in provision for the elderly was identified and it was also felt that there was a lack of awareness of the existence of advocacy for this group in nursing homes. About half of the "generic" Mental Health Advocacy Organisations that completed the survey provided advocacy for people over the age of 65 . Whilst there was an obvious gap in Mental Health Advocacy Services for the elderly there was rapid development in this area. However, it was not clear to what extent this was a strategic development as some Age Concern organisations that were contacted during the survey had no plans to develop an advocacy service even though there was no other provision in that borough. Furthermore, there was a lack of comprehensive services for the elderly even where there was some provision. For instance, of the organisations providing Mental Health Advocacy for the elderly, many did not have specialist advocates to work with people with dementia whereas others only had advocates to work with people with dementia and not other Mental Health problems. Even those with specialist advocates for people with dementia could not always work with people under the age of 65 . So in spite of apparent increasing provision there were some anomalies in funding which continued to leave areas of unmet need.

A gap in advocacy for carers was identified as was some potential conflict of interest. The relationship between advocates and carers can be problematic in terms of maintaining strict boundaries about confidentiality and independence. This is particularly the case when following an instructed advocacy model and advocates are reluctant to pursue carers' requests for advocacy on behalf of the person they care for. Furthermore, carers themselves have advocacy needs (Carers Advisory Group, 2001). There was also a perceived gap in the provision of Mental Health Advocacy for lesbians and gay men. There was one London wide organisation for lesbians and gay men that do not have the resources 
to cover the whole of London. None of the other organisations had targeted workers for lesbians and gay men and many said that lesbian and gay service users would not feel safe enough to access a lesbian and gay Advocacy Scheme via a more generic Mental Health Advocacy Scheme. Participants said that more lesbian and gay Mental Health Advocacy Schemes should be developed and/or better ways of liasing with the specialist lesbian and gay Advocacy Scheme needed to be developed so that service users across London could access it.

Many advocacy schemes said that they lacked the capacity and resources to train and support volunteers and user involvement which might have contributed to advocacy functions. It was hard to gauge from the survey the extent of user involvement in advocacy services although there was a great deal of variety. In terms of volunteer numbers (who may or may not have been users) it was difficult to determine if volunteers were working specifically on advocacy projects or generally within a larger organisation. Many advocacy providers commented that user involvement could be difficult to sustain. In relation to self-advocacy $69 \%$ of the organisations who returned the survey said they supported it and several ran courses in selfadvocacy. About half of the organisations provided group advocacy of which half included Patient Council Schemes. Less than a fifth provided citizen advocacy. Increasing capacity through user involvement may require a more eclectic approach to models of advocacy, incorporating more group, self, and citizen advocacy, so that user involvement could focus on developing support structures rather than adhering solely to an instructed model.

Service users and advocates felt that there were some gross inequalities in funding within London and it was suggested that central funding might improve this although there were concerns about central control (Scottish Executive, 2001; National Disability Authority, 2003). It is unclear what the impact of central funding might have on providing more specialist services for minority groups. In a telephone interview with one scheme for minority ethnic groups there was a strong feeling that small organisations lacked the infrastructure to compete for funding. There was also a strong feeling that once larger organisations took on minority issues they were fundamentally changed and the service delivered was not as appropriate as that provided by grassroots groups. Service users also felt that the independence of advocacy schemes could be com- promised if they were funded by local Mental Health Trusts. Commissioner's views on these issues were sought.

All the commissioners agreed that commissioning should be a collaborative rather than a competitive process but centralisation of funding was opposed by most respondents. Most did not agree that independence was compromised by local commissioning and felt that the local knowledge secured through this approach was invaluable. However, it was also felt that the process of local commissioning did not always adequately cater for specialist and minority needs or those in the community.

\section{Conclusion}

The analysis reported above raised questions about the geographical scale at which equity in provision should be considered. The geographical mapping of Mental Health Advocacy Services in London identified a greater clustering in the Inner London area to broadly match higher need in those parts of the city as measured by admission rates (Fig. 1). The mapping also identified broadly equitable provision of services across the capital with each borough being served by at least one local service as well as by London wide specialist schemes. However at a local level, no borough has the full range of specialist provision, which matched local demography and no one organisation had a full range of services in terms of specialist provision and where the service was targeted. Additionally, the lack of reach of advocacy services into community settings highlighted spatial gaps noted in wider Mental Health Care Provision (Milligan, 2000; Parr, 2000).

The study also highlighted the diversity of groups using Mental Health Services, which implied a need for diverse advocacy well adapted to each group and user involvement seemed to have been underused in this respect. This may reflect the work of Parr (2000) on the inclusion and exclusion of people with Mental Health problems and the extent to which it was problematic to see them as a homogenous group. There were gaps in provision for many groups who were minorities and/or had specialist needs. Many of these groups benefitted most from a style of advocacy that incorporated both personal advocacy with support and working with communities, as well as instructed advocacy. This model of advocacy provision cost more per case but was perhaps the most cost-effective 
method. It was also perhaps the most likely approach to enable closer working with communities and in the community and the most likely method to increase capacity for user involvement and empowerment. The findings also threw some light on discussions by Wolch and Philo (2000) around sites of resistance and it could be argued that the sites of Mental Health Advocacy could become foci in the future for ongoing tensions between service providers and service users which may have the capacity to harm as well as support strategic coalitions and Mental Health alliances.

The study revealed the rather marginal position of advocacy services in terms of consideration for funding and the problems of providing services when secure funding was not assured. Mapping the information gathered from the questionnaire and focus groups provided additional perspectives on inequalities in provision. These included a less even spread of organisations providing $100 \%$ advocacy (Fig. 3) and a considerable variation in resources available to advocacy services when measured by funding per case (Fig. 4). From a specific service provision perspective, existing advocacy services were clearly operating in a climate of instability and uncertainty, which seriously affected future service planning.

From a data and information perspective, there were a number of significant issues, which arose in the course of the project. These included data access, confidentiality and data protection, currency, comparability and gaps in linking up primary and acute Mental Health Care Data (O'Dwyer \& Burton, 1998). All of these would need to be extensively developed in any subsequent work on service delivery. A particularly important issue that arose related to data and information on Community Mental Health Data, which were relatively poor compared with data for acute inpatient services and better integrated information might provide a particularly profitable direction for future research (Emslie et al., 2002).

The findings were also consistent with other studies in the geography of Mental Health which suggest that care settings need to be considered both in terms of physical location and service catchments designed to match need/demand while the study also illustrated the need to consider the setting or institution where advocacy was provided as a social space. The role of place and setting was also clearly important. Curtis (2004) identified some examples of the structural factors (administrative, political, social and spatial) which influence landscapes of consumption and which change depending on context and time. Administrative and spatial factors were clearly important as contextual settings in this study, while time played a hitherto unconsidered 'barrier role' due to uncertainties in future funding and the short-term nature of that funding.

There were clear links in the study back to geographies of power/resistance (e.g. reviewed in relation to health geography by Curtis 2004). In an environment where services are driven (with the best intentions) by service providers who are constrained by funding, service models and their own roles, there was continuing evidence of power issues related to the advocacy needs of users and their ability to receive the general and specialist services they needed. In line with wider research in health geographies (Wellstood, Wilson, \& Eyles, 2006) notions of equity of access to meet need was affected by a set of barriers which could be both spatial and aspatial or more specifically individual and system-related. From this perspective, in the case of advocacy provision, what ultimately affected the ability of users to access appropriate services were the structures of services provision and the lack of flexibility within that system to meet the specialist user needs of a complex and heterogeneous group.

\section{Acknowledgements}

The authors would like to thank all of the organisations that assisted with, and provided information for, the research. Particular thanks must go to the NHS Executive Steering Group and Greater London Mental Health Advocacy Network (GLMHAN). The London Public Health Observatory also provided some key data. This paper is an extension of an earlier presentation at the GeoHealth Conference held at Victoria University, Wellington, New Zealand in December 2002. It is also an abbreviated version of a finished report presented to the GLMHAN and NHS Executive.

\section{References}

Atkinson, D. (1999). Advocacy - a review. Brighton: Pavilion for Joseph Rowntree Foundation.

Baker, E. A., Boulding, N., Durham, M., Lowell, M. E., Gonzalez, M., Jodaitis, N., et al. (1997). The Latino health advocacy program: A collaborative lay health advisor approach. Health Education Behavior, 24(4), 495-509. 
Barnes, D. (2001). Specialist mental health advocacy. Presentation at Greater London mental health advocacy network annual conference. November 5th, London.

Barnes, M., Davis, A., \& Tew, J. (2000). There ought to be a way...users' experiences of compulsion under the 1983 Mental Health Act. Birmingham: University of Birmingham.

Bhana, A., \& Pillay, Y. G. (1998). Use of the geographical information system (GIS) to determine potential access and allocation of public mental health resources in KwaZuluNatal. South African Journal of Psychology, 28(4), 222-233.

Bhui, K. (1997). London's ethnic minorities and the provision of mental health services. In S. Johnson, et al. (Eds.), London's mental health: The report to the London King's Fund Commission (pp. 143-166). London: King's Fund.

Brandon, D., \& Simpson, T. (2001). Regulation agitation. Open Mind, 107, 16-17.

Bullen, N., Moon, G., \& Jones, K. (1996). Defining localities for health planning - a GIS approach. Social Science \& Medicine, 42(6), 801-816.

Buston, K. (2002). Adolescents with mental health problems: What do they say about health services? Journal of Adolescence, 25(2), 231-242.

Carers Advisory Group. (2001). A Charter for those who provide help and support to individuals experiencing mental health problems: Valuing carers. London: The London Mental Health Carers' Charter.

Chahal, K. (1999). Minority ethnic homelessness in London. Findings from a rapid review. London: NHSE.

Curran, C., \& Grimshaw, C. (2000). Advocacy. Open Mind, 101, 28.

Curtis, S., \& Lawson, K. (2000). Gender, ethnicity and selfreported health: The case of African Caribbean populations in London. Social Science \& Medicine, 50, 365-385.

Curtis, S., \& Taket, A. (1996). Health and societies: Changing perspectives. London: Edward Arnold.

Curtis, S. (2004). Health \& inequalities. London: Sage.

Davies, S., Thornicroft, G., Leese, M., Higgingbotham, A., \& Phelan, M. (1996). Ethnic differences in risk of compulsory admission among representative cases of psychosis in London. British Medical Journal, 312(7030), 533-537.

Dear, M., \& Wolch, J. (1997). Landscapes of Despair: From Institutionalization to Homelessness. Oxford: Polity Press.

Dembling, B., Li, X., Chang, W., Mackey, S., \& Merwin, E. (2001). Psychiatric health service areas in the Southeast. Administration and policy in mental health, 28(5), 407-416.

Department of Health. (1998). Modernising mental health services-safe, sound and supportive. London: Stationary Office.

Dunn, S. (1999). Creating accepting communities: Report of the MIND Inquiry into social inclusion and mental health problems. London: Mind.

Emslie, C., Fuhrer, R., Hunt, K., Macintyre, S., Shipley, M., \& Stansfeld, S. (2002). Gender differences in mental health: Evidence from three organisations. Social Science \& Medicine, 54(4), 621-624.

Fitzpatrick, J., \& Jacobson, B. (2001). Mapping health inequalities across London. London: London Public Health Observatory.

Foulks, E. F. (2000). Advocating for persons who are mentally ill, a history of mutual empowerment of patients and profession. Administration and Policy in Mental Health, 27, 353-367.

Gath, C., \& Higginson, I. (1995). Report of the mental health census. A point prevalence study. Joint project to identify people with severe and enduring mental health problems in Kensington and Chelsea and Westminster. Department of Public Health, Kensington and Chelsea and Westminster Commissioning Agency.

Gatrell, A., \& Senior, M. (1999). Health and health care applications. In P. Longley, et al. (Eds.), Geographical information systems: Principles, techniques, applications and management (pp. 925-938). London: Wiley.

Gatrell, A. (2002). Geographies of health. London: Blackwell.

Gell, C. (1990). User group Involvement. In L. Winn (Ed.), Power to the people: The key to responsive services in health and social care. London: King's Fund Centre.

Giggs, J. A., \& Cooper, J. E. (1987). Ecological structure and the distribution of schizophrenia and affective psychoses in Nottingham. British Journal of Psychiatry, 151, 627-633.

Glover, G., Leese, M., \& McCrone, P. (1999). More severe mental illness is more concentrated in deprived areas. British Journal of Psychiatry, 175, 544-548.

Greater London Mental Health Advocacy Network (GLMHAN). (2001). The Greater London mental health advocacy network: Who we are and where we're going - plans for 2001-2005. London: GLMHAN.

Grimshaw, C. (1996). Awaaz: An Asian self-advocacy project. Open Mind, 79, 13.

Harrison, J., Barrow, S., \& Creed, F. (1995). Social deprivation and psychiatric admission rates among different diagnostic groups. British Journal of Psychiatry, 167, 456-462.

Harvey, C. (1996). The Camden Schizophrenia surveys I. The psychiatric, behavioural and social characteristics of the severely mentally ill in Inner London. British Journal of Psychiatry, 168, 410-417.

The Health of Londoners Project. (1998). Housing and health in London: A review by the health of Londoners project. London: Health of Londoners' project.

Henderson, R., \& Pochin, M. (2001). A right result? Advocacy, justice and empowerment. Bristol: The Policy Press.

Hirshorn, B. A., \& Stewart, J. E. (2001). Use of GIS for planning and service delivery to at-risk older populations. Gerontologist, 41(SI1), 243.

Johnson, S., Ramsay, R., Thornicroft, G., Brooks, L., Lelliott, P., Peck, E., et al. (1998). London's mental health: The report to the London King's Fund Commission. London: King's Fund Publishing.

Johnson, S., \& Taylor, R. (2001). Statistics of mentally disordered offenders 2000. Home Office Statistical Bulletin, 22-01.

Jones, K., \& Moon, G. (1987). Health, disease and society: A critical medical geography. London: Routledge \& Kegan Paul.

Joseph, A. E., \& Phillips, D. R. (1984). Accessibility and utilization: Geographical perspectives on health care delivery. New York: Harper \& Row.

Kearns, R., \& Gesler, W. (Eds.). (1996). Putting health into place. Syracuse: Syracuse University Press.

Lamont, A., Ukoumunne, O., Tyrer, P., Thornicroft, G., \& Slaughter, J. (2000). The geographical mobility of severely mentally ill residents in London. Social Psychiatry and Psychiatric Epidemiology, 35(4), 164-169.

Lewis, L. (2001). The role of mental health patient organisations in disease management-Focus on the US National Depressive and Manic-Depressive Association. Disease Management and Health Outcomes, 9(11), 607-617. 
London Research Centre. (1999). Focus on London '99. London: LRC.

Matz, D., Hill, R., \& Heath, T. (2001). Asylum Statistics United Kingdom 2000. Home Office Statistical Bulletin, 17/01, 45.

McLafferty, S. L. (2003). GIS and health care. Annual Review of Public Health, 24, 25-42.

Meltzer, H., et al. (1995). The prevalence of psychiatric morbidity among adults living in private households. OPCS surveys of psychiatric morbidity in Great Britain. London: HMSO.

Milligan, C. (2000). Breaking out of the Asylum': The impact of the informal sector in a restructured mental health environment. Health and Place, 6(3), 189-200.

Morgan, D., Bardsley, M., \& Dawson, I. (2000). Mapping health for primary care groups. The changing geography of health in London. London: Health of Londoners Project, NHSE London Regional Office.

Morgan, D. L., \& Kreuger, R. A. (1993). 'When to use focus groups and why'. In D. L. Morgan (Ed.), Successful Focus Groups. London: Sage.

Morselli, P. L., \& Elgie, R. (2000). Present and future role of mental illness advocacy associations in the management of the mentally ill, realities, needs and hopes at the edge of the third millennium. Bipolar Disorders, 2, 294-300.

Munn, P. (2001). CYMAR. The Advocate, August, 12-13.

National Disability Authority. (2003). Exploring Advocacy. Dublin: National Disability Authority.

NHS Executive and Social Services Inspectorate. (2001). Mental health in London: A strategy for action. London: NHS Executive London.

O'Dwyer, L., \& Burton, D. (1998). Potential meets reality: GIS and public health research in Australia. Australian and New Zealand Journal of Public Health, 22(7), 819-823.

Oliver, C., \& Warwick, I. (2004). The PACE mental health advocacy project: An evaluation - final report. London: Thomas Coram Research Unit, Institute of Education, University of London.

Openshaw, S. (1984). The modifiable areal unit problem: Concepts and Techniques in Modern Geography, Vol. 38. Norwich: Geo Books.

Parr, H. (1997). Mental health, public space and the city: Questions of individual and collective access. Environment \& Planning D: Society \& Space, 15, 435-454.

Parr, H. (1999). Bodies and psychiatric medicine: interpreting different geographies of mental health. In R. Butler, \& H. Parr (Eds.), Mind and Body Spaces: Geographies of Illness, Impairment and Disability. London: Routledge.

Parr, H. (2000). Interpreting the 'hidden social geographies' of mental health: Ethnographies of inclusion and exclusion in semi-institutional places. Health \& Place, 6(3), 225-238.

Phillips, R. L., Kinman, E. L., Schnitzer, P. G., Lindbloom, E. J., \& Ewigman, B. (2000). Using geographic information systems to understand health care access. Archives of Family Medicine, 9(10), 971-978.

Platzer, H. (2000) Lesbian and gay advocacy and training project: An independent evaluation of the first year of operation. MIND in Brighton and Hove.

Platzer, H. (2002) Report to the swap consortium on the advocacy needs of service users in London. Cyrenians Housing; Opendoor Housing Trust; St Martin of Tours Housing Association and Alcohol Recovery Project.

Platzer, H., \& Foley, R. (2004). Mental health advocacy in London. A mapping report. London Development Centre. http://www.londondevelopmentcentre.org/downloads/mappingreport1.pdf.
Pyke, J., Morris, L., Rabin, K., \& Sabriye, A. A. (2001). Improving accessibility: The experience of a Canadian mental health agency. Psychiatric Rehabilitation Journal, 25(2), 180-185.

Rai-Atkins, A. (2002). Best practice in mental health : Advocacy for African, Caribbean and South Asian communities. Bristol: The Policy Press.

Richards, T. B., Croner, C. M., Rushton, G., Brown, C. K., \& Fowler, L. (1999). Geographic information systems and public health: Mapping the future. Public Health Reports, 114(4), 359-373.

Robson, G. (1987). Nagging: Models of advocacy. In I. Barker, \& E. Peck (Eds.), Power in strange places: User empowerment in mental health services. London: Good Practices in Mental Health.

Rogers, A., \& Pilgrim, D. (1996). Mental Health Policy in Britain: A Critical Introduction. London: Macmillan.

Rose, D. (2001). Users' voices: The perspectives of mental health service users on community and hospital care. London: The Sainsbury Centre for Mental Health.

Rushton, G. (1998). Improving the geographic basis of health surveillance using GIS. In A. Gatrell, \& M. Löytönen (Eds.), GIS and Health (GISDATA 6) (pp. 63-79). London: Taylor \& Francis.

The Sainsbury Centre for Mental Health. (1998). Acute problems: A survey of the quality of care in acute psychiatric wards. London: The Sainsbury Centre for Mental Health.

Scott, J. (1993). Homelessness and mental illness. British Journal of Psychiatry, 162, 314-324.

Scottish Executive. (2001). Independent advocacy: A guide for commissioners. Edinburgh: The Stationery Office Bookshop.

Scottish Human Services Trust. (2002). Independent advocacy in Scotland, from patchwork to blanket - the lessons learned from the production of the first round of advocacy plans. Edinburgh: SHS Trust.

SIGN. (1998). Mental health services for deaf people: Are they appropriate? A study carried out by sign, an organisation that campaigns for deaf people with mental health problems, with funding from the Department of Health. Beaconsfield: SIGN.

Silvera, M., \& Kapasi, R. (2000). Health advocacy for minority ethnic Londoners: Putting services on the map. London: King's Fund Publishing.

Smaje, C. (1995). Health, 'race' and ethnicity: Making sense of the evidence. London: King's Fund Institute.

Stevenson, J. (2001). Mapping local rehabilitation and intermediate care services; a whole systems approach to understanding service capacity and planning change. London: King's Fund Publishing.

Thornicroft, G. (1991). Social deprivation and rates of treated mental disorder, developing statistical models to predict psychiatric service utilisation. British Journal of Psychiatry, 158, 475-484.

Travers, T., \& Minors, M. (1995). London 95. London: London Research Centre.

Wellstood, K., Wilson, K., \& Eyles, J. (2006). 'Reasonable access' to primary care: assessing the role of individual and system characteristics. Health \& Place, 12(2), 121-130.

Wilson, M., \& Francis, J. (1997). Raised voices: AfricanCaribbean and African users' views and experiences of mental health services in England and Wales. London: MIND.

Wolch, D., \& Philo, C. (2000). From distributions of deviance to definitions of difference: Past and future mental health geographies. Health and Place, 6(3), 137-158. 